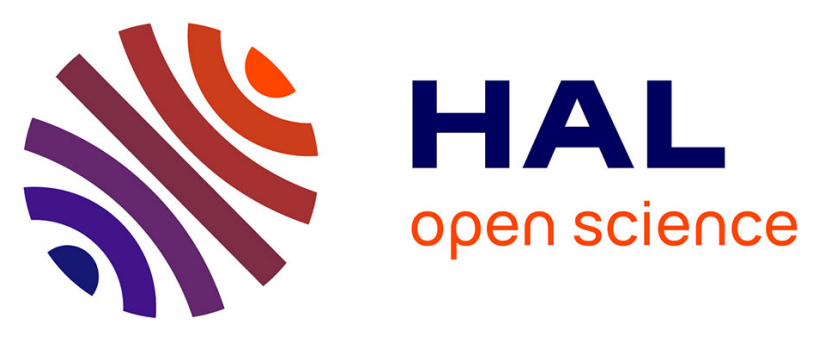

\title{
Extremely high prevalence of multidrug resistant tuberculosis in Murmansk, Russia: a population-based study
}

J. Mäkinen, M. Marjamäki, M. Haanperä-Heikkinen, H. Marttila, L. B. Endourova, S. E. Presnova, V. Mathys, P. Bifani, R. Ruohonen, M. K. Viljanen, et al.

\section{To cite this version:}

J. Mäkinen, M. Marjamäki, M. Haanperä-Heikkinen, H. Marttila, L. B. Endourova, et al.. Extremely high prevalence of multidrug resistant tuberculosis in Murmansk, Russia: a population-based study. European Journal of Clinical Microbiology and Infectious Diseases, 2011, 30 (9), pp.1119-1126. 10.1007/s10096-011-1200-7 . hal-00677967

\section{HAL Id: hal-00677967 https://hal.science/hal-00677967}

Submitted on 11 Mar 2012

HAL is a multi-disciplinary open access archive for the deposit and dissemination of scientific research documents, whether they are published or not. The documents may come from teaching and research institutions in France or abroad, or from public or private research centers.
L'archive ouverte pluridisciplinaire HAL, est destinée au dépôt et à la diffusion de documents scientifiques de niveau recherche, publiés ou non, émanant des établissements d'enseignement et de recherche français ou étrangers, des laboratoires publics ou privés. 


\section{Extremely High Prevalence of Multidrug Resistant Tuberculosis in Murmansk, Russia- A population based study}

Johanna Mäkinen ${ }^{1}$, Merja Marjamäki ${ }^{1}$, Marjo Haanperä-Heikkinen ${ }^{1 *}$, Harri Marttila ${ }^{1}$, Larisa B. Endourova ${ }^{2}$, Svetlana E. Presnova ${ }^{2}$, Vanessa Mathys ${ }^{3}$, Pablo Bifani ${ }^{3}$, Rauni Ruohonen ${ }^{4}$, Matti K. Viljanen ${ }^{5}$ and Hanna Soini ${ }^{1}$

${ }^{1}$ Antimicrobial resistance unit, Mycobacterial Laboratory, National Institute for Health and Welfare, Turku, Finland, ${ }^{2}$ Murmansk Regional TB Dispensary, Murmansk, The Russian Federation,

${ }^{3}$ Molecular Pathology of Tuberculosis, Communicable and Infectious Diseases, Scientific Institute of Public Health, Bruxelles, Belgium, ${ }^{4}$ Finnish Lung Health Association, Helsinki, Finland, ${ }^{5}$ Department of Medical Microbiology and Immunology, University of Turku, Turku, Finland

* Corresponding author. Mailing address: Mycobacterial Laboratory, Antimicrobial resistance unit, National Institute for Health and Welfare, Kiinamyllynkatu 13, 20520 Turku, Finland. Phone: 35820-610-6628. Fax: 358-20-610-6699. Email: marjo.haanpera-heikkinen@thl.fi.

Running title: MDR-TB in Murmansk 


\begin{abstract}
Drug resistance and molecular epidemiology of tuberculosis (TB) in Murmansk region was investigated in a two-year, population based surveillance of the civilian population. During 2003 and 2004, isolates from all culture positive cases were collected $(n=1226)$. Prevalence of multi-drug resistance (MDR) was extremely high, as 114 of 439 new cases (26.0\%), and 574 of 787 previously treated cases $(72.9 \%)$ were resistant to at least isoniazid (INH) and rifampin (RIF). Spoligotyping of the primary MDR-TB isolates revealed that most isolates grouped to the Beijing SIT1 genotype ( $n=$ 91, 79.8\%). Isolates of this genotype were further analyzed by IS6110 RFLP. Sequencing of gene targets associated with INH and RIF resistance further showed that the MDR-TB strains are highly homogenous as $78 \%$ of the MDR, SIT1 strains had the same resistance conferring mutations. The genetic homogeneity of the MDR-TB strains indicates that they are actively transmitted in Murmansk.
\end{abstract}

Keywords: Mycobacterium tuberculosis, multi-drug resistance, Spoligotyping, rpoB, katG 


\section{Introduction}

Tuberculosis (TB) remains the world's deadliest curable infectious disease. In 2007 alone, there were an estimated 9.27 million new reported cases and 1.77 million deaths [1]. The problem is further exacerbated by the growing number of cases of multidrug-resistant TB (MDRTB), accounting for 511,000 reported cases in 2007. MDR-TB is caused by Mycobacterium tuberculosis isolates resistant to at least isoniazid (INH) and rifampin (RIF) [2]. The acute spread of TB and MDR-TB in the Russian Federation has led the WHO to designate it as the $11^{\text {th }}$ highest TB burden country in the world; although recently the rising levels of MDR-TB have been reversed in the Russian oblast of Orel and Tomsk [1]. The case notification data in parts of Russia is increasingly accompanied by the phenomenon of drug-resistance [3], making successful treatment and control of the disease difficult. The situation has become even more critical with the emergence of extensively drug resistant tuberculosis (XDR-TB) defined as MDR strains which are additionally resistant to the second line fluoroquinolones and at least one injectable drug (amikacin, kanamycin or capreomycin) [4]. Since this study was carried out in 2003-2004, "MDR-TB" comprises both MDR and XDR-TB isolates.

Since the implementation of $M$. tuberculosis genotyping, one group of clinical isolates, the "Beijing/W family", has received considerable attention [5]. These strains have been shown to be highly prevalent throughout East Asia and the countries of the former Soviet Union, and have often been associated with community outbreaks, global transmission, and drug resistance $[5,6]$. The Beijing strains have also been associated with TB treatment failures and relapse cases [7]. It has been further proposed that Beijing strains have some selective advantage over others [8]. 
Since 1997, a collaborative agreement on TB control has been established between Finland and the bordering regional government of Murmansk, the Russian Federation. The aim of the project "Improvement of prevention and treatment of tuberculosis in the Murmansk Region", implemented by the Finnish Lung Health Association (FILHA) and the Murmansk TB Dispensary, was to assist the regional tuberculosis program to combat the growing TB epidemic, drug-resistant TB cases, and reduce the number of cases of tuberculosis associated mortality and morbidity. The project strategy was based on the international recommendations of the WHO and the International Union Against Tuberculosis and Lung Disease (IUATLD). This study is a part of the project.

Murmansk region is situated in North Western Russia by the Arctic sea. The total population of the region is of 885.000 inhabitants, of which 370.000 live in the city of Murmansk. A steady increase in TB notification rates was observed in Murmansk region as for the rest of the Russian Federation since 1991. The peak of TB notification was registered in 2000 (72.4 cases per 100000 inhabitants) followed by a decrease to 56.6 and 62.6 per 100000 people in 2001 and 2002, respectively. During this period the reported primary (untreated patients) MDR-TB cases were 11 and 13 accounting for 6.5 and $7.3 \%$ of all new cases reported in 2000 and 2001 [9, 10]. During the years 1999 - 2002, treatment failure rates of new cases and relapses increased from $2.8 \%$ to $16.5 \%$ and from $9.1 \%$ to $36.4 \%$, respectively. Overall mortality due to TB per 100000 inhabitants increased from 5.6 in 1999 to 11.5 in 2002 . Nonetheless, the rate remained lower than in other parts of the Russian Federation including Northwest Russia. The DOTS program (Direct Observed Short Course Therapy) was introduced gradually to the region reaching full geographical coverage in 2002. In 2003 and 2004, the tuberculosis notification rates in Murmansk oblast comprised 396 and 451 tuberculosis cases, corresponding to incidences 51.7 and 43.1 per 100000 people, respectively. The prevalence of human immunodeficiency virus (HIV) infection in the region in 2003 and 2004 was 147 and 137 cases (www.epinorth.org) and nine new HIV-TB co-infection cases were found both in 2003 and 2004 (personal communication, Rauni Ruohonen, FILHA). Nonetheless, it has 
been suspected that these numbers are under-estimates given the limited resources, infrastructure, inadequate laboratory facilities, standardization, quality control, and detection available. In addition, the increased treatment failure and mortality rates suggest that the actual number of MDRcases is considerably higher than reported

The aims of this two-year population based study were to properly determine the frequency and characteristics of MDR-TB in the Murmansk region of the Russian Federation using molecular epidemiology techniques. The present study on the prevalence of drug resistant tuberculosis was carried out in the certified new TB-facilities in Murmansk following the recommendation of the WHO [11], and the performance of the new Murmansk TB Dispensary was also evaluated. Our results identify an extremely elevated number of cases of clustered MDR-TB in the region.

\section{Materials and Methods}

\section{Bacterial isolates and Drug Susceptibility Testing}

A total of 1226 M. tuberculosis isolates, representing all culture positive cases, were collected from civilian TB patients during the years 2003 and 2004 by the regional TB dispensary in Murmansk. $35.8 \%$ of the patients $(n=439)$ had never been treated for TB (new cases) while $64.2 \%$ ( $n=787$ ) had been previously treated for TB (Table 1). Drug susceptibility testing (DST) was conducted for the four first-line drugs INH, RIF, streptomycin (STR), and ethambutol (EMB) by the proportion method on Löwenstein-Jensen media according to the WHO guidelines [12]. The performance of the DST was evaluated with a parallel analysis of a blind subset of isolates $(n=149)$ in the Finnish Mycobacterial Reference Laboratory using the same methods as in the newly certified facilities in Murmansk. Furthermore, isolates that gave discrepant results between phenotypic DST and known genotypic markers associated with drug resistance were subjected to 
further DST analysis by BD BACTEC MGIT 960 SIRE (BD Biosciences, Sparks, MD, USA) for confirmation.

\section{Spoligotyping and IS6110 RFLP}

M. tuberculosis isolates from new cases $(\mathrm{n}=439)$ were subjected to spoligotyping according to standard recommendations [13]. The spoligotyping results were entered in binary format (1 and 0) according to the hybridization results (positive or negative) as Excel (Microsoft, CA) spreadsheets. The spoligotype SIT (Spoligo-International Type Number) was determined by comparing the patterns to those in the international spoligotype database of the Institute Pasteur of Guadeloupe (The SITVIT http://www.pasteurguadeloupe.fr:8081/SITVITDemo/index.jsp).

The primary MDR-TB isolates that could not be discriminated by spoligotyping (the Beijing SIT1 isolates, $n=91$ ) were further genotyped by IS6110 RFLP [14]. The RFLP data was analyzed using the BioNumerics v.4.01 software (Applied Maths, Inc., Sint-Martens-Latem, Belgium) and unweighted pair-group method of arithmetic averaging with the Dice coefficient and $1 \%$ position tolerance settings for cluster analysis. The UPGMA method clusters the pair of isolates that are most similar to each other first, and then clusters the next-most similar isolates, until all isolates are analyzed. A cluster was defined as two or more isolates that were indistinguishable by IS6110 RFLP and spoligotype patterns.

\section{Molecular characterization of drug resistance}

The $r p o B$ and $k a t G$ genes of phenotypically MDR isolates from new cases $(\mathrm{n}=114)$ were sequenced as previously described [14-16]. The complete $r p o B$ gene and flanking 100bp were sequenced for phenotypically MDR isolates encoding a wild type rifampin resistance-determining region (RRDR, 81bp). All samples were sequenced in the forward and reverse directions. 


\section{Results}

This two-year population based study revealed an extremely high prevalence of MDRTB in the Murmansk region (Table 1). In total, 688 (56.1\%) of all isolates were resistant to at least INH and RIF. Primary MDR-TB was encountered in 114 of the 439 new cases (26.0\%) and in 574 of the $787(72.9 \%)$ previously treated patients .Only 419 isolates $(34.2 \%)$ were fully susceptible, while 119 (9.7\%) displayed drug resistance other than MDR. An integral part of the project was the quality control of the DST results obtained in Murmansk. Parallel analysis of 149 M. tuberculosis isolates showed that the overall concordance during the study period was $94.0 \%$. The accuracy of individual drugs was $93.4 \%$ for INH, $98.7 \%$ for RIF, $96.0 \%$ for EMB and $87.8 \%$ for STR.

M. tuberculosis isolates from new cases were subjected to genotyping. As such, 437 $(99.5 \%)$ of the 439 isolates were successfully spoligotyped to 82 different spoligotypes of which 48 (389 isolates) matched known SITs while 34 were new spoligopatterns not previously deposited in the international spoligotype database of the Institute Pasteur of Guadeloupe. Furthermore, 387 isolates $(88.6 \%)$ grouped into 34 different spoligoclusters having between 2 to 184 isolates per cluster while 50 isolates had a unique spoligotype. Of the clustered isolates, $367(94.8 \%)$ belonged to a spoligotype having a matching spoligotype profile in the SITVIT database and the remaining 20 isolates $(5.2 \%)$ belonged to eight spoligotypes not retrievable from the spoligotype database (Table 2). Among the 34 clusters, 12 contained five or more isolates and were defined as major clusters which comprised $86.8 \%(\mathrm{n}=336)$ of the clustered isolates. The largest cluster, the SIT1 spoligotype of the Beijing family, comprised 184 M. tuberculosis isolates (41.9\% of all new cases). Accordingly, the majority of the primary MDR-TB isolates (108/114, 94.7\%) displayed a spoligopattern present in the SITVIT database and 92 (80.7\%) MDR-TB isolates belonged to the Beijing family spoligotypes SIT1 or SIT255 (Table 2). The MDR Beijing SIT1 isolates (n=91) were further sub-grouped using IS6110 RFLP. Twelve distinct clusters involving 73 isolates (80\%) were recognized. The largest IS6110 cluster had 29 isolates (32\%), and the remaining 11 clusters 
included 2 to 9 isolates each (Figure 1). The IS6110 patterns of 18 MDR Beijing isolates were unique in this study. The number of IS6110 copies per isolate varied from 12 to 21 .

The $k a t G$ and $r p o B$ genes of the primary MDR isolates $(n=114)$ were sequenced in order to identify the mutations associated with the INH and RIF resistance, respectively. Ser315Thr $(\mathrm{AGC} \rightarrow \mathrm{ACC})$ mutation in $k a t G$ occurred in $97.4 \%(n=111)$ of the sequenced isolates (Table 3). All the Beijing SIT1 and SIT255 isolates $(\mathrm{n}=92)$ contained $k a t G$ Arg463Leu (CGG $\rightarrow$ CTG) single nucleotide polymorphism (SNP). This SNP is characteristic of isolates belonging to the principal genetic grouping 1 (PPG1) [17]. Two phenotypically isoniazid resistant isolates encoded a wild type $k a t G$ gene and one Beijing isolate had only the Arg463Leu SNP in the katG. One Beijing SIT1 isolate contained an additional silent GGC-> GGA mutation on codon 451Gly.

The $r p o B$ Ser531Leu (TCG $\rightarrow$ TTG) mutation was found in $87(76.3 \%)$ of the primary MDR isolates, including 74 Beijing SIT1 isolates (Table 3). The second most commonly found SNP was on codon rpoB526 in which four different mutations were found in 13 isolates (11\%) representing various spoligotypes. Five of the rpoB526 mutants had additional rpoB mutations within the RRDR. Three isolates shared dual Leu511Pro and His526 mutations. In 2 Beijing SIT1 isolates, multiple rроB mutations were found, one isolate encoded His526Leu and an in-frame deletion of codons 508-509 and the other had 4 point mutations on codons 512, 525,526 and 527 (Table 3). These isolates were clustered by IS6110 RFLP (clusters 6 and 12, Figure 1). Based on the IS6110 fingerprinting and spoligotyping data, no indication of double infection was found. Original samples of all isolates encoding multiple SNPs within the rpoB were re-sequenced from fresh isolates in order to rule-out sequencing errors or selection of mutants from the sub-culture. Finally, 4 other isolates had mutations on codon rpoB516 and $10(8.8 \%)$ rifampin resistant isolates encoded a wild type RRDR in the $r p o B$. Correlation of the rifampin resistant but wild type RRDR isolates with spoligopatterns showed that 9/10 grouped to Beijing SIT1 family, and 1 to SIT262. Judging by 
IS6110 RFLP, only one of the 9 Beijing SIT1 family members was clustered (cluster 16, Figure 1), and the remaining 8 isolates represented unique IS6110 fingerprints. Interestingly, the SIT262 wild type $r p o B$ isolate also had wild type kat $\mathrm{G}$. The entire $r p o \mathrm{~B}$ gene and 100 nucleotides upstream were sequenced for the 10 rifampin-resistant isolates encoding a wild type RRDR fragment. Seven of the nine Beijing-type isolates were found to encode a SNP on codon Ser450Leu (TCG>TTG) in addition to the silent mutation on codon 1075 (GCG>GCT).

\section{Discussion}

This is the first population-based report on the prevalence of M. tuberculosis drug resistance in Murmansk. Our drug resistance surveillance results during 2003 to 2004 revealed that a quarter $(26.0 \%)$ of all new TB cases and three quarters $(72.9 \%)$ of the re-treatment cases comprised MDR-TB, resulting in a rapid overall increase in the cumulative number of MDR cases. This is the highest rate of MDR prevalence among both new and re-treatment cases in a civilian population ever reported [3, 18, 19] to our knowledge, although the situation is very similar in Azerbaijan, where nearly a quarter of all new TB cases (22.3\%) are MDR [20]. The high mortality (15\% and 22\% in years 2003 and 2004) and treatment failure (11\% and 17\% in 2003 and 2004, respectively) rates in the Murmansk Region could most likely be attributed to the elevated number of MDR cases. The high level of MDR tuberculosis in these regions may partly be due to the difficulties in the drug logistics that occurred in Russia after the collapse of the Soviet Union. Due to the difficulties, TB patients were treated with separate drugs instead of the recommended fourdrug regimen, which may have contributed to the development of the antibiotic resistance.

TB control in the Murmansk Region has remained difficult and the problems with treatment adherence and DOTS are persistent while working with a socially marginalized population. The problem is exacerbated with the elevated numbers of MDR and HIV co-infection. Well-functioning DOTS program, coupled with accurate timely diagnosis and laboratory 
identification is a prerequisite for effective management of MDR-TB. This is only possible while laboratory diagnostics and DST is reliable and includes appropriate quality control. Timely detection of drug-resistant TB, and adequate treatment regimens administered early in the course of the disease, are essential in the prevention of primary transmission [21]. The results of this study confirm the accuracy of DST results obtained by the central TB laboratory of Murmansk region. It also shows the extreme high proportion of MDR cases among newly detected cases, reflecting the ongoing transmission of MDR in the society.

The use of a rapid test for RIF-resistance, a surrogate marker for MDR, is an excellent method for identifying MDR-TB strains. Patients infected with RIF-resistant or MDR strains that are rapidly identified can be properly isolated and placed on alternative anti-microbial treatment regiments [21]. In this study, $91.2 \%$ of the MDR-TB isolates could have been identified by screening the RRDR region of the $r p o B$ gene. The profiles of mutations associated with drug resistance observed in this study coupled with those reported in the literature allows to utilize existing or design new molecular markers targeting specific SNPs to accelerate the identification process of RIF-resistant isolates. For example, SNP specific primers targeting rpoB mutations 531 and 526 [22] may be used upfront while susceptibility tests are still under evaluation gaining valuable time and allowing for adequate treatment and isolation procedures.

All isolates obtained from new cases were characterized by genotyping (spoligotyping) and the MDR-TB isolates of new TB patients were further analyzed by sequencing of the kat $\mathrm{G}$ and $r p o B$ genes. In addition, MDR isolates belonging to the SIT1 genotype were further genotyped by IS6110 RFLP. Comparison of spoligotypes from Murmansk with the international spoligotyping database SpolDB4 [8], revealed that the majority $(389 / 437,89.0 \%)$ of the isolates belonged to known SIT patterns. Several families of M. tuberculosis strains have been recognized based on spoligotypes including Beijing, T, Haarlem $(\mathrm{H})$ and LAM. In this study, most samples 
grouped to the Beijing strain family $(44 \%, n=193$, SIT1, SIT255, SIT260 and SIT269). This is similar to the findings from the Archangel oblast (44.5\%) [23] and to the results of a study containing $36 \mathrm{~TB}$ isolates from the Murmansk region, of which $47.2 \%$ represented Beijing spoligotypes [24]. The most prevalent spoligotype of this study, SIT1, included $41.9 \%$ of the isolates and $79.8 \%$ of the MDR isolates. The SIT1 spoligotype is characteristic of the Beijing/W family, which is known for its frequent association with MDR, outbreaks and high emergence worldwide. The prevalence of Beijing isolates in Russia, both in prisons and in the community, and the high rate of MDR typical for this group have been recognized in a number of studies $[5,6,23$, 25-27]. Our results are consistent with this observation and demonstrate that the Beijing genotype plays an important role in the epidemiology of MDR-TB in civilian population of this high incidence region of the North-Western Russia.

Clustering of IS6110 fingerprints has been used to estimate the amount of recent transmission in a population [28]. The high proportion $(80 \%, n=73)$ of IS6110 clustered Beijing isolates, as well as the fact that one quarter of new TB cases are MDR-TB, indicates that these MDR-TB strains are actively transmitted throughout the community. The rate of IS6110 clustered MDR cases (80\%) is similar to that observed in Hungary (75\%) [29] but lower than in reports from Estonia $(95.8 \%)[23,30]$.

The most common resistance mutation found in primary MDR isolates was the katG Ser315Thr mutation AGC $\rightarrow$ ACC $(n=109,95.6 \%)$. This is consistent with the observation that unusually high proportion of Ser315Thr mutation is characteristic of INH-resistant strains in Russia [31-33]. As previously reported, mutations in codons 531, 526 and 516 of $r p o B$ are responsible for 86-100\% of RIF-resistant TB cases in Russia in agreement with other global reports originating from regions with high rates of MDR-TB [34]. This was also seen in Murmansk, where mutations in codon rpoB531 accounted for $91.2 \%(n=104)$ of the RIF resistance among the primary MDR 
isolates. The rpoB531 mutation was more prevalent among the Beijing than the non Beijing MDR strains $(81.5 \%$ and $54.5 \%)$, whereas the Ser315Thr in katG was highly prevalent independently of the genotype. There are conflicting reports concerning the correlation of prevalence of mutations and spoligotypes [35-37], suggesting that the association of particular mutations and Beijing genotype could be a regional evolutionary phenomenon. The biased presentation of resistance mutations in the Beijing family strains observed in some former Soviet Union countries could be due to frequent spread of particular resistant and virulent clones of the Beijing genotype.

No SNPs within the 81bp RRDR were found in 10 (8.8\%) rifampin-resistant isolates. Complete sequencing of the rpoB identified mutation Ser450Leu (TCG>TTG) in seven of these isolates. However, correlation between this newly reported SNP and rifampin resistance has not been confirmed. Likewise, this mutation is has not been reported in the TB Drug Resistance Database (http://www.tbdreamdb.com/RIF_Rv0667_AllMutations.html). The absence of SNPs within the RRDR has been reported in approximately $10 \%$ of MDR cases in other studies [33, 38] indicating that other resistance mechanisms are also involved and should be studied. Two isolates presented with multiple mutations in rрoB. Based on the fingerprinting data, no indication of dual infection was found in these isolates. Dual or multiple mutations in the $r p o B$ have been reported Kazakhstan [37], Turkey [39] Belarus [40] and South Korea [41] to mention a few.

\section{Conclusions}

An extremely high prevalence of MDR-TB combined with an ongoing active transmission of the Beijing genotype was observed in Murmansk. Early case finding is crucial for prevention of the spread of MDR-TB. Since INH and RIF resistance in Murmansk was caused by "common" mutations, molecular assays targeting these mutations can be used for rapid detection of MDR-TB in most cases. Thus, introduction of molecular methods suitable for rapid detection of MDR-TB could improve disease management and decrease the transmission rate in this area. 


\section{Conflict of interest}

The authors declare that they have no conflict of interest. 


\section{References}

1. WHO. (2009) WHO REPORT 2009: Global Tuberculosis Control Epidemiology, Strategy, Financing. World Health Organization.

2. Espinal MA (2003) The global situation of MDR-TB. Tuberculosis (Edinb). 83(1-3):44-51.

3. Aziz MA, Wright A, Laszlo A, De Muynck A, Portaels F, Van Deun A, Wells C, Nunn P, Blanc L and Raviglione M (2006) Epidemiology of antituberculosis drug resistance (the Global Project on Anti-tuberculosis Drug Resistance Surveillance): an updated analysis. Lancet. 368(9553):2142-2154.

4. Centers for Disease Control and Prevention (2006) Emergence of Mycobacterium tuberculosis with Extensive Resistance to Second-Line Drugs -- Worldwide, 2000-2004. (Cover story). MMWR: Morbidity \& Mortality Weekly Report. 55(11):301-305.

5. Bifani PJ, Mathema B, Kurepina NE and Kreiswirth BN (2002) Global dissemination of the Mycobacterium tuberculosis W-Beijing family strains. Trends Microbiol. 10(1):45-52.

6. Glynn JR, Whiteley J, Bifani PJ, Kremer K and van Soolingen D (2002) Worldwide occurrence of Beijing/W strains of Mycobacterium tuberculosis: a systematic review. Emerg Infect Dis. 8(8):843-849.

7. Lan NT, Lien HT, Tung le B, Borgdorff MW, Kremer K and van Soolingen D (2003) Mycobacterium tuberculosis Beijing genotype and risk for treatment failure and relapse, Vietnam. Emerg Infect Dis. 9(12):1633-1635.

8. Brudey K, Driscoll JR, Rigouts L, Prodinger WM, Gori A, Al-Hajoj SA, Allix C, Aristimuno L, Arora J, Baumanis V, Binder L, Cafrune P, Cataldi A, Cheong S, Diel R, Ellermeier C, Evans JT, Fauville-Dufaux M, Ferdinand S, Garcia de Viedma D, Garzelli C, Gazzola L, Gomes HM, Guttierez MC, Hawkey PM, van Helden PD, Kadival GV, Kreiswirth BN, Kremer K, Kubin M, Kulkarni SP, Liens B, Lillebaek T, Ho ML, Martin C, Martin C, Mokrousov I, Narvskaia O, Ngeow YF, Naumann L, Niemann S, Parwati I, Rahim Z, Rasolofo-Razanamparany V, Rasolonavalona T, Rossetti ML, Rusch-Gerdes S, Sajduda A, Samper S, Shemyakin IG, Singh UB, Somoskovi A, Skuce RA, van Soolingen D, Streicher EM, Suffys PN, Tortoli E, Tracevska T, Vincent V, Victor TC, Warren RM, Yap SF, Zaman K, Portaels F, Rastogi N and Sola C (2006) Mycobacterium tuberculosis complex genetic diversity: mining the fourth international spoligotyping database (SpolDB4) for classification, population genetics and epidemiology. BMC Microbiol. 6:23.

9. Madaras T, Danilovits M and Mariandyshev A (2002) Murmansk-Finland tuberculosis project Phase II Evaluation 1997-2001. Project No F/122703.

10. Madaras T and Danilovits M (2005) Murmansk-Finland tuberculosis project Phase II Evaluation 2002-2004. Project No F/122703.

11. World Health Organisation, Guidelines for surveillance of drug resistance in tuberculosis. 2 nd ed. WHO/CDS/TB/2003/320, ed. M.A. Aziz, et al. 2003, Geneva: WHO.

12. Canetti G FW, Khomenko A, Mahler N, Menon NK, Mitchison DA, Rist N, and Smeley NA. (1969) Advances in techniques of testing mycobacterial drug sensitivity, and the use of sensitivity tests in tuberculosis control programmes. Bull. WHO. 41:21-43.

13. Kamerbeek J, Schouls L, Kolk A, van Agterveld M, van Soolingen D, Kuijper S, Bunschoten A, Molhuizen H, Shaw R, Goyal M and van Embden J (1997) Simultaneous detection and strain differentiation of Mycobacterium tuberculosis for diagnosis and epidemiology. J Clin Microbiol. 35(4):907-914.

14. Marttila HJ, Soini H, Vyshnevskiy BI, Otten TF, Vasilyef AV, Huovinen P and Viljanen MK (1998) Rapid detection of rifampin-resistant Mycobacterium tuberculosis by sequencing and line probe assay. Scand J Infect Dis. 30(2):129-132. 
15. Marttila HJ, Soini H, Huovinen P and Viljanen MK (1996) katG mutations in isoniazidresistant Mycobacterium tuberculosis isolates recovered from Finnish patients. Antimicrob Agents Chemother. 40(9):2187-2189.

16. Bifani PJ, Plikaytis BB, Kapur V, Stockbauer K, Pan X, Lutfey ML, Moghazeh SL, Eisner W, Daniel TM, Kaplan MH, Crawford JT, Musser JM and Kreiswirth BN (1996) Origin and interstate spread of a New York City multidrug-resistant Mycobacterium tuberculosis clone family. Jama. 275(6):452-457.

17. Sreevatsan S, Pan X, Stockbauer KE, Connell ND, Kreiswirth BN, Whittam TS and Musser JM (1997) Restricted structural gene polymorphism in the Mycobacterium tuberculosis complex indicates evolutionarily recent global dissemination. Proc Natl Acad Sci U S A. 94(18):9869-9874.

18. WHO (2007) Global tuberculosis control: surveillance, planning, financing (WHO/HTM/TB/2007.376).

19. Viljanen MK, Vyshnevskiy BI, Otten TF, Vyshnevskaya E, Marjamäki M, Soini H, Laippala PJ and Vasilyef AV (1998) Survey of drug-resistant tuberculosis in northwestern Russia from 1984 through 1994. Eur J Clin Microbiol Infect Dis. 17(3):177-183.

20. WHO (2008) Anti-tuberculosis drug resistance in the world. Report No. 4.

21. WHO (2006) Guidelines for the programmatic management of drug-resistant tuberculosis. (WHO/HTM/TB 2006.361).

22. Dubiley S, Mayorova A, Ignatova A, Kirillov E, Stepanshina V, Kolesnikov A and Shemyakin I (2005) New PCR-based assay for detection of common mutations associated with rifampin and isoniazid resistance in Mycobacterium tuberculosis. Clin Chem. 51(2):447-450.

23. Toungoussova OS, Sandven P, Mariandyshev AO, Nizovtseva NI, Bjune G and Caugant DA (2002) Spread of drug-resistant Mycobacterium tuberculosis strains of the Beijing genotype in the Archangel Oblast, Russia. J Clin Microbiol. 40(6):1930-1937.

24. Baranov AA, Mariandyshev AO, Mannsåker T, Dahle UR and Bjune GA (2009) Molecular epidemiology and drug resistance of widespread genotypes of Mycobacterium tuberculosis in northwestern Russia. Int J Tuberc Lung Dis. 13:1288-1293.

25. Ruddy M, Balabanova Y, Graham C, Fedorin I, Malomanova N, Elisarova E, Kuznetznov S, Gusarova G, Zakharova S, Melentyev A, Krukova E, Golishevskaya V, Erokhin V, Dorozhkova I and Drobniewski F (2005) Rates of drug resistance and risk factor analysis in civilian and prison patients with tuberculosis in Samara Region, Russia. Thorax. 60(2):130135 .

26. Mokrousov I, Filliol I, Legrand E, Sola C, Otten T, Vyshnevskaya E, Limeschenko E, Vyshnevskiy B, Narvskaya O and Rastogi N (2002) Molecular characterization of multipledrug-resistant Mycobacterium tuberculosis isolates from northwestern Russia and analysis of rifampin resistance using RNA/RNA mismatch analysis as compared to the line probe assay and sequencing of the rpoB gene. Res Microbiol. 153(4):213-219.

27. Drobniewski F, Balabanova Y, Nikolayevsky V, Ruddy M, Kuznetzov S, Zakharova S, Melentyev A and Fedorin I (2005) Drug-resistant tuberculosis, clinical virulence, and the dominance of the Beijing strain family in Russia. Jama. 293(22):2726-2731.

28. Van Soolingen D (2001) Molecular epidemiology of tuberculosis and other mycobacterial infections: main methodologies and achievements. J Intern Med. 249(1):1-26.

29. Ködmön C, Niemann S, Lukács J, Sör E, Dávid S and Somoskövi A (2006) Molecular epidemiology of drug-resistant tuberculosis in Hungary. J Clin Microbiol. 44(11):42584261.

30. Kruuner A, Hoffner SE, Sillastu H, Danilovits M, Levina K, Svenson SB, Ghebremichael S, Koivula T and Kallenius G (2001) Spread of drug-resistant pulmonary tuberculosis in Estonia. J Clin Microbiol. 39(9):3339-3345. 
31. Nikolayevsky V, Brown T, Balabanova Y, Ruddy M, Fedorin I and Drobniewski F (2004) Detection of mutations associated with isoniazid and rifampin resistance in Mycobacterium tuberculosis isolates from Samara Region, Russian Federation. J Clin Microbiol. 42(10):4498-4502.

32. Marttila HJ, Soini H, Eerola E, Vyshnevskaya E, Vyshnevskiy BI, Otten TF, Vasilyef AV and Viljanen MK (1998) A Ser315Thr substitution in KatG is predominant in genetically heterogeneous multidrug-resistant Mycobacterium tuberculosis isolates originating from the St. Petersburg area in Russia. Antimicrob Agents Chemother. 42(9):2443-2445.

33. Ignatova A, Dubiley S, Stepanshina V and Shemyakin I (2006) Predominance of multidrug-resistant LAM and Beijing family strains among Mycobacterium tuberculosis isolates recovered from prison inmates in Tula Region, Russia. J Med Microbiol. 55(Pt 10):14131418.

34. Ramaswamy S and Musser JM (1998) Molecular genetic basis of antimicrobial agent resistance in Mycobacterium tuberculosis: 1998 update. Tuber Lung Dis. 79:3-29.

35. Qian L, Abe C, Lin TP, Yu MC, Cho SN, Wang S and Douglas JT (2002) rpoB genotypes of Mycobacterium tuberculosis Beijing family isolates from East Asian countries. J Clin Microbiol. 40(3):1091-1094.

36. Lipin MY, Stepanshina VN, Shemyakin IG and Shinnick TM (2007) Association of specific mutations in $k a t G, r p o B, r p s L$ and $r r s$ genes with spoligotypes of multidrug-resistant Mycobacterium tuberculosis isolates in Russia. Clin Microbiol Infect. 13(6):620-626.

37. Hillemann D, Kubica T, Agzamova R, Venera B, Rusch-Gerdes S and Niemann S (2005) Rifampicin and isoniazid resistance mutations in Mycobacterium tuberculosis strains isolated from patients in Kazakhstan. Int J Tuberc Lung Dis. 9(10):1161-1167.

38. Shemyakin IG, Stepanshina VN, Ivanov IY, Lipin MY, Anisimova VA, Onasenko AG, Korobova OV and Shinnick TM (2004) Characterization of drug-resistant isolates of Mycobacterium tuberculosis derived from Russian inmates. Int $\mathbf{J}$ Tuberc Lung Dis. 8(10):1194-1203.

39. Aktas E, Durmaz R, Yang D and Yang Z (2005) Molecular characterization of isoniazid and rifampin resistance of Mycobacterium tuberculosis clinical isolates from Malatya, Turkey. Microb Drug Resist. 11(2):94-99.

40. Titov LP, Zakerbostanabad S, Slizen V, Surkova L, Taghikhani M and Bahrmand A (2006) Molecular characterization of rроB gene mutations in rifampicine-resistant Mycobacterium tuberculosis isolates from tuberculosis patients in Belarus. Biotechnol J. 1(12):1447-1452.

41. Park YK, Shin S, Ryu S, Cho SN, Koh WJ, Kwon OJ, Shim YS, Lew WJ and Bai GH (2005) Comparison of drug resistance genotypes between Beijing and non-Beijing family strains of Mycobacterium tuberculosis in Korea. J Microbiol Methods. 63(2):165-172. 
Table 1. Drug susceptibility test results in Murmansk

\begin{tabular}{llll}
\hline New cases & $\mathbf{2 0 0 3}(\boldsymbol{\%})$ & $\mathbf{2 0 0 4}(\boldsymbol{\%})$ & Total $(\boldsymbol{\%})$ \\
\hline Total tested & 197 & 242 & 439 \\
Total susceptible & $125(63.5)$ & $147(60.7)$ & $272(62.0)$ \\
Any resistance & $72(36.5)$ & $95(39.3)$ & $167(38.0)$ \\
MDR & $47(23.9)$ & $67(27.7)$ & $114(26.0)$ \\
& & & \\
\hline Previously treated cases & $\mathbf{2 0 0 3 ( \% )}$ & $\mathbf{2 0 0 4}(\boldsymbol{\%})$ & Total $(\boldsymbol{\%})$ \\
\hline Total tested & 399 & 388 & 787 \\
Total susceptible & $69(17.3)$ & $78(20.1)$ & $147(18.7)$ \\
Any resistance & $330(82.7)$ & $310(79.9)$ & $640(81.3)$ \\
MDR & $296(74.2)$ & $278(71.6)$ & $574(72.9)$ \\
\hline
\end{tabular}


Table 2. Prevalence $M$. tuberculosis spoligotype clusters $(\mathrm{n}=34)$ found in Murmansk.

\begin{tabular}{|c|c|c|c|c|}
\hline $\mathbf{S I T}^{\mathrm{a}}$ & Family $^{\mathrm{b}}$ & $N^{\mathrm{c}}$ & $\%$ & $\boldsymbol{n}(\mathbf{M D R})^{d}$ \\
\hline 1 & Beijing & 184 & 47.5 & 91 \\
\hline 255 & Beijing & 3 & 0.8 & 1 \\
\hline 260 & Beijing & 2 & 0.5 & 0 \\
\hline 269 & Beijing-like & 4 & 1.0 & 0 \\
\hline 262 & $\mathrm{H} 4$ & 28 & 7.2 & 3 \\
\hline 35 & $\mathrm{H} 4$ & 21 & 5.4 & 0 \\
\hline 762 & $\mathrm{H} 4$ & 2 & 0.5 & 0 \\
\hline 1134 & $\mathrm{H} 4$ & 2 & 0.5 & 1 \\
\hline 50 & H3 & 7 & 1.8 & 2 \\
\hline 47 & $\mathrm{H} 1$ & 10 & 2.6 & 2 \\
\hline 531 & $\mathrm{H} 1$ & 8 & 2.1 & 1 \\
\hline 1155 & $\mathrm{H} 1$ & 3 & 0.8 & 0 \\
\hline 42 & LAM9 & 16 & 4.1 & 5 \\
\hline 53 & $\mathrm{~T} 1$ & 15 & 3.9 & 0 \\
\hline 264 & $\mathrm{~T} 1$ & 6 & 1.6 & 0 \\
\hline 205 & $\mathrm{~T} 1$ & 2 & 0.5 & 0 \\
\hline 498 & $\mathrm{~T} 1$ & 2 & 0.5 & 0 \\
\hline 766 & $\mathrm{~T} 1$ & 2 & 0.5 & 0 \\
\hline 280 & T1-RUS & 3 & 0.8 & 0 \\
\hline 1173 & T1-RUS2 & 3 & 0.8 & 0 \\
\hline 52 & $\mathrm{~T} 2$ & 26 & 6.7 & 0 \\
\hline 560 & $\mathrm{U}$ & 10 & 2.6 & 0 \\
\hline 1562 & $\mathrm{U}$ & 2 & 0.5 & 0 \\
\hline 254 & T5-RUS1 & 2 & 0.5 & 0 \\
\hline 40 & $\mathrm{~T} 4$ & 2 & 0.5 & 0 \\
\hline 482 & $\mathrm{BCG}^{\mathrm{e}}$ & 2 & 0.5 & 0 \\
\hline 577763777720771 & $\mathrm{ND}^{\mathrm{f}}$ & 2 & 0.5 & 0 \\
\hline 747637777760771 & ND & 2 & 0.5 & 0 \\
\hline 777467607760771 & ND & 2 & 0.5 & 2 \\
\hline 777763774020771 & ND & 5 & 1.3 & 0 \\
\hline 777770774020771 & ND & 2 & 0.5 & 2 \\
\hline 777777347760411 & ND & 2 & 0.5 & 0 \\
\hline 777777763760771 & ND & 2 & 0.5 & 0 \\
\hline 777741001760771 & ND & 3 & 0.8 & 0 \\
\hline Total & & 387 & 100 & 110 \\
\hline
\end{tabular}

${ }^{a}$ SIT, designation of the spoligotype in the international database (http://www.pasteurguadeloupe.fr:8081/SITVITDemo/trouverSIT.jsp). If a SIT designation was not found in the database, the spoligotype is described by its octacode.

${ }^{\mathrm{b}}$ spoligotype family designated in SPOLDB4 [8].

${ }^{\mathrm{c}}$ Number of isolates having a certain spoligotype

${ }^{\mathrm{d}}$ Number of MDR isolates having a certain spoligotype

${ }^{\mathrm{e}}$ M. bovis $\mathrm{BCG}$

${ }^{\mathrm{f}} \mathrm{ND}$, spoligotype not designated in SpolDB4 [8]. 
2 Table 3. Characterization of MDR-TB isolates by spoligotyping and rpoB and kat $\mathrm{G}$ gene sequencing.

\begin{tabular}{|c|c|c|c|c|c|}
\hline SIT $^{\mathrm{a}}$ & Clade or octacode $\mathrm{b}^{\mathrm{b}}$ & katG & rpoB & $n$ & $\%$ \\
\hline \multirow[t]{8}{*}{1} & Beijing & 315 ACC, 463 CTG & 531 TTG & 71 & 62.3 \\
\hline & & 315 ACC, 463 CTG & $526 \mathrm{GAC}$ & 6 & 5.3 \\
\hline & & 315 ACC, 463 CTG & wt & 9 & 7.9 \\
\hline & & 315 ACC, 463 CTG & Deletion codons 508, 509; 526 CTC & 1 & 0.9 \\
\hline & & $315 \mathrm{ACC}, 463 \mathrm{CTG}$ & 512 AGA, 525 ACG, 526 TCC, $527 \mathrm{CAG}$ & 1 & 0.9 \\
\hline & & 315 ACC, 451 GGA, 463 CTG & $531 \mathrm{TTG}$ & 1 & 0.9 \\
\hline & & 463 CTG & 531 TTG & 1 & 0.9 \\
\hline & & wt & 531 TTG & 1 & 0.9 \\
\hline \multirow[t]{2}{*}{42} & LAM-9 & $315 \mathrm{ACC}$ & $526 \mathrm{GAC}$ & 2 & 1.8 \\
\hline & & $315 \mathrm{ACC}$ & $511 \mathrm{CCG}, 526 \mathrm{AAG}$ & 3 & 2.6 \\
\hline 47 & $\mathrm{H}-1$ & 315 AGA & 531 TTG & 2 & 1.8 \\
\hline 50 & $\mathrm{H}-3$ & 315 ACC & 531 TTG & 2 & 1.8 \\
\hline 237 & $\mathrm{U}$ & 315 ACC & 516 TTC & 1 & 0.9 \\
\hline 255 & Beijing & 315 ACC, 463 CTG & $531 \mathrm{TTG}$ & 1 & 0.9 \\
\hline \multirow[t]{3}{*}{262} & $\mathrm{H}-4$ & $315 \mathrm{ACC}$ & 516 GTC & 1 & 0.9 \\
\hline & & $315 \mathrm{ACC}$ & 531 TTG & 1 & 0.9 \\
\hline & & wt & wt & 1 & 0.9 \\
\hline 531 & $\mathrm{H}-1$ & $315 \mathrm{ACC}$ & $531 \mathrm{TTG}$ & 1 & 0.9 \\
\hline 746 & $\mathrm{H}-3$ & $315 \mathrm{ACC}$ & 531 TTG & 1 & 0.9 \\
\hline
\end{tabular}




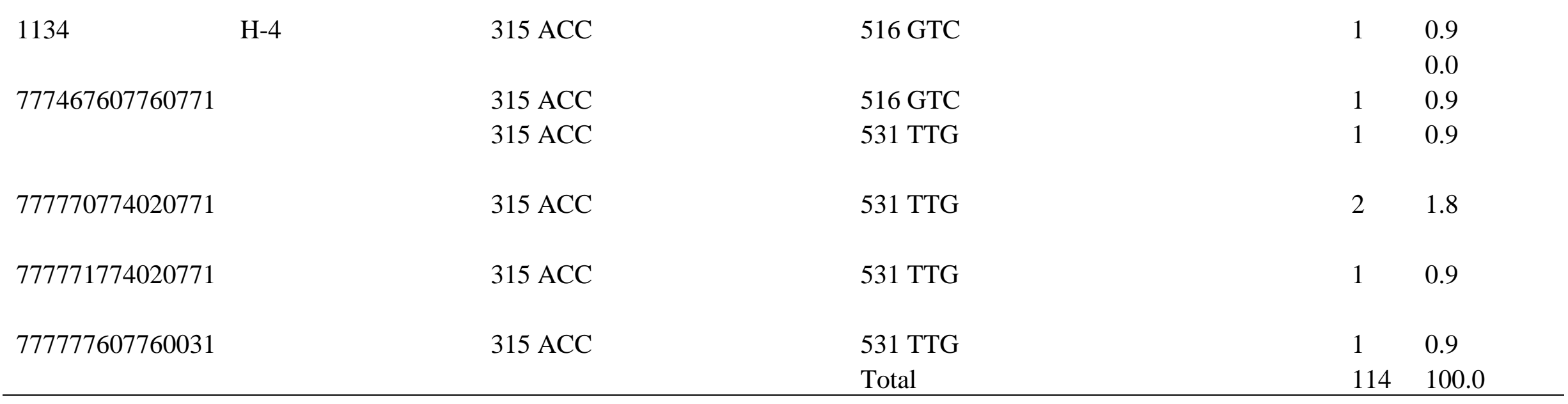

${ }^{a}$ SIT, designation of the spoligotype in the international database (http://www.pasteur-guadeloupe.fr:8081/SITVITDemo/trouverSIT.jsp). If a SIT designation was not found in the database, the spoligotype is described by its octacode.

${ }^{\mathrm{b}}$ Clade, defined as described in [8]: LAM: Latin American and Mediterranean, H: Haarlem, U: undefined. 
9 Figure1. IS6110 RFLP dendrogram of Beijing (SIT1) MDR-TB strains.

$10 \mathrm{n}=$ number of isolates in defined RFLP cluster)

11

12 


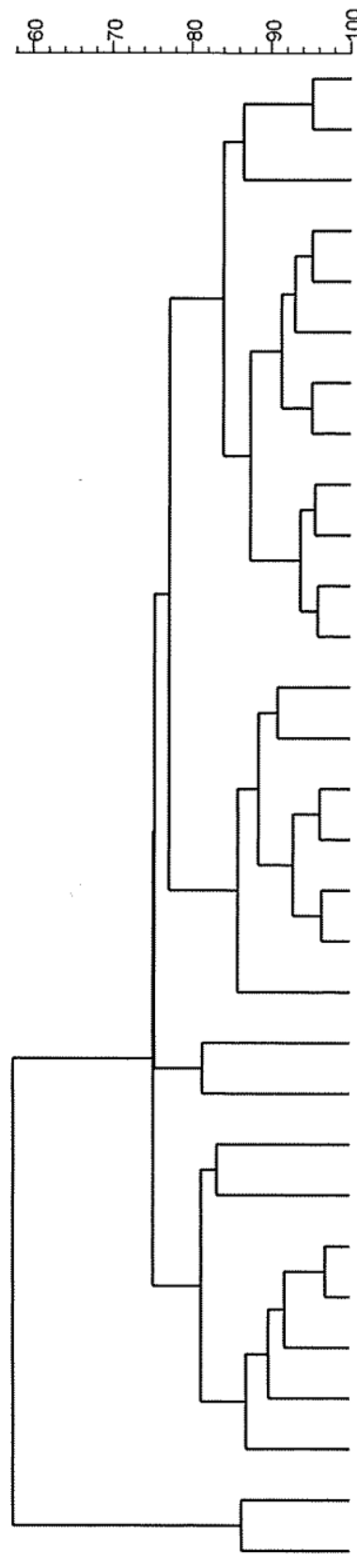

|| || || | ||

| I||| || ||

| | | || ||

| ||| || ||||

|| || ||

| ||| || |||

||| || |||

| | | || ||| ||

||||| || ||

||||| || |||

\|III| || ||

|| |||| || ||||

|||||||||||||||| $\mid$

||||||||||||||||

IIII|| || || $\mid$

||||||| ||| |||

|l|||||| || ||

|||||||| || ||||

||| |||||||| || |||

|||||||| |||

|||||||||| ||||

| | | |||| ||||

|| || |||| |||

|| |||||||||| ||||

|l| ||| |||||| ||||

||| ||||||| ||||

| ||||||||||||||

|||||||||||| $\mid$

|||||||| | || || ||

||||||||| || ||||||| ||
INH RIF STR EMB Cluster

$\begin{array}{lllll}R & R & R & R & \text { Not clustered }\end{array}$

$\begin{array}{lllll}R & R & R & R & \text { Not clustered }\end{array}$

$\begin{array}{lllll}\mathrm{R} & \mathrm{R} & \mathrm{R} & \mathrm{R} & \text { Not clustered }\end{array}$

$\begin{array}{lllll}\mathrm{R} & \mathrm{R} & \mathrm{R} & \mathrm{R} & \text { Not clustered }\end{array}$

$\begin{array}{lllll}\mathrm{R} & \mathrm{R} & \mathrm{R} & \mathrm{R} & \text { MUR } 5\end{array}$

$\begin{array}{lllll}R & R & R & R & \text { Not clustered }\end{array}$

$\begin{array}{lllll}R & R & R & R & \text { Not clustered }\end{array}$

$\begin{array}{lllll}R & R & R & R & \text { Not clustered }\end{array}$

$\begin{array}{lllll}R & R & S & R & M U R \\ & R\end{array}$

$\begin{array}{lllll}\mathrm{R} & \mathrm{R} & \mathrm{R} & \mathrm{R} & \mathrm{MUR} 4\end{array}$

$\begin{array}{lllll}R & R & S & R & M U R \\ 11\end{array}$

$\begin{array}{lllll}R & R & R & R & \text { Not clustered }\end{array}$

$\begin{array}{lllll}R & R & R & R & \text { MUR 9 }\end{array}$

$\begin{array}{lllll}R & R & R & R & \text { Not clustered }\end{array}$

$\begin{array}{lllll}\mathrm{R} & \mathrm{R} & \mathrm{R} & \mathrm{R} & \mathrm{MUR} 8\end{array}$

$\begin{array}{lllll}R & R & S & R & M U R 7\end{array}$

$\begin{array}{lllll}\mathrm{R} & \mathrm{R} & \mathrm{R} & \mathrm{R} & \mathrm{MUR} 6\end{array}$

29

$\begin{array}{lllll}R & R & S & R & \text { Not clustered }\end{array}$

$\begin{array}{lllll}R & R & S & R & \text { Not clustered }\end{array}$

$\begin{array}{lllll}R & R & R & R & \text { Not clustered }\end{array}$

$\begin{array}{lllll}R & R & R & S & \text { Not clustered }\end{array}$

$\begin{array}{lllll}R & R & R & R & \text { Not clustered }\end{array}$

$R \quad R \quad R \quad R \quad$ Not clustered

$\begin{array}{llllll}R & R & R & S & M U R & 3\end{array}$

$\begin{array}{llllll}\mathrm{R} & \mathrm{R} & \mathrm{R} & \mathrm{R} & \mathrm{MUR} 2 & 2\end{array}$

$\begin{array}{llllll}\mathrm{R} & \mathrm{R} & \mathrm{R} & \mathrm{R} & \mathrm{MUR} 1 & 3\end{array}$

$\begin{array}{lllll}\mathrm{R} & \mathrm{R} & \mathrm{R} & \mathrm{R} & \text { Not clustered }\end{array}$

$\begin{array}{lllll}R & R & R & R & \text { Not clustered }\end{array}$

$\begin{array}{lllll}\mathrm{R} & \mathrm{R} & \mathrm{R} & \mathrm{R} & \text { MUR } 12\end{array}$

10

$\begin{array}{lllll}\mathrm{R} & \mathrm{R} & \mathrm{R} & \mathrm{R} & \text { Not clustered }\end{array}$ 